\title{
Engineering students' attitudinal beliefs by gender and student division: a methodological comparison of changes over time
}

\author{
Madison E. Andrews@, Anita D. Patrick@ and Maura Borrego* (1)
}

\begin{abstract}
Background: Students' attitudinal beliefs related to how they see themselves in STEM have been a focal point of recent research, given their well-documented links to retention and persistence. These beliefs are most often assessed cross-sectionally, and as such, we lack a thorough understanding of how they may fluctuate over time. Using matched survey responses from undergraduate engineering students $(n=278)$, we evaluate if, and to what extent, students' engineering attitudinal beliefs (attainment value, utility value, self-efficacy, interest, and identity) change over a 1-year period. Further, we examine whether there are differences based on gender and student division, and then compare results between cross-sectional and longitudinal analyses to illustrate weaknesses in our current understanding of these constructs.
\end{abstract}

Results: Our study revealed inconsistencies between cross-sectional and longitudinal analyses of the same dataset. Cross-sectional analyses indicated a significant difference by student division for engineering utility value and engineering interest, but no significant differences by gender for any variable. However, longitudinal analyses revealed statistically significant decreases in engineering utility value, engineering self-efficacy, and engineering interest for lower division students and significant decreases in engineering attainment value for upper division students over a one-year period. Further, longitudinal analyses revealed a gender gap in engineering self-efficacy for upper division students, where men reported higher means than women.

Conclusions: Our analyses make several contributions. First, we explore attitudinal differences by student division not previously documented. Second, by comparing across methodologies, we illustrate that different conclusions can be drawn from the same data. Since the literature around these variables is largely cross-sectional, our understanding of students' engineering attitudes is limited. Our longitudinal analyses show variation in engineering attitudinal beliefs that are obscured when data is only examined cross-sectionally. These analyses revealed an overall downward trend within students for all beliefs that changed significantly-losses which may foreshadow attrition out of engineering. These findings provide an opportunity to introduce targeted interventions to build engineering utility value, engineering self-efficacy, and engineering interest for student groups whose means were lower than average.

Keywords: Retention, Longitudinal studies, Gender, Expectancy value theory

\footnotetext{
* Correspondence: maura.borrego@austin.utexas.edu
}

The University of Texas at Austin, Austin, TX, USA

\section{Springer Open}

(c) The Author(s). 2021 Open Access This article is licensed under a Creative Commons Attribution 4.0 International License, which permits use, sharing, adaptation, distribution and reproduction in any medium or format, as long as you give appropriate credit to the original author(s) and the source, provide a link to the Creative Commons licence, and indicate if changes were made. The images or other third party material in this article are included in the article's Creative Commons licence, unless indicated otherwise in a credit line to the material. If material is not included in the article's Creative Commons licence and your intended use is not permitted by statutory regulation or exceeds the permitted use, you will need to obtain permission directly from the copyright holder. To view a copy of this licence, visit http://creativecommons.org/licenses/by/4.0/. 


\section{Introduction}

Despite perennial calls to address issues of retention and persistence in engineering, the overall 4-year graduation rate remains below 35\% for undergraduate students (Yoder, 2017). Six-year graduation rates are higher, nearing $60 \%$, but the fact remains that $40 \%$ of engineering students are lost before graduation; further, $20 \%$ of students are lost within the first year alone (Yoder, 2017). Not surprisingly, then, the attitudes and beliefs that may help explain persistence have been a perennial topic of interest in engineering education research (e.g., Marra et al. 2009), and more broadly, in STEM education research (e.g., Xie et al. 2015). There is a wide body of literature examining factors that contribute to undergraduate students' choices to persist in STEM disciplines; namely, domain-specific identity beliefs, selfefficacy, interest, and various subjective task value beliefs have consistently been linked to persistence in STEM (e.g., Blackburn, 2017; Hill et al. 2010; Wang and Degol, 2017).

Yet, the body of literature that examines these attitudinal beliefs in engineering is incomplete in several ways. First, despite evidence that proves these beliefs are malleable (e.g., Mamaril and Royal, 2008), the extant studies on student attitudes and engineering persistence typically rely on data collected at a single time point. That is, prior studies are largely crosssectional in nature (e.g., Godwin and Lee, 2017). These studies use comparisons across student division (i.e., lower or upperclassmen) as a proxy for changes over time. These cross-sections of students include only upperclassmen who have persisted in the degree program, which may bias our understanding of engineering attitudes. The few longitudinal studies (e.g., Jones et al. 2010; Matusovich et al. 2010) yield mixed or inconclusive results.

In all, our understanding of undergraduate students' engineering attitudinal beliefs remains limited, despite wide acknowledgement of their importance in retention. Thus, the purpose of this study is to analyze these beliefs with respect to time, student division, and gender. Specifically, our study seeks to answer the following questions:

1) To what extent do students' engineering attitudinal beliefs (attainment value, utility value, self-efficacy, interest, and identity) differ over time and by students' gender when analyzed (a) cross-sectionally and (b) longitudinally?

2) What conclusions would be drawn or ignored by using only one analysis approach?

This research addresses several crucial gaps in the literature. First, we disaggregate our data by both gender and student division, the latter of which is not frequently examined in the engineering education literature. Additionally, we compare results from both cross-sectional and longitudinal analyses of identical variables, using the above research questions to guide our analyses and structure presentation of results. By doing so, we aim to both illustrate that research design can vastly impact the conclusions one draws from a study and to recommend stronger, longitudinal methodologies for future work in this area. Further, the findings of this study could lead to direct action in the improvement of retention rates and enhancement of diversity by identifying areas in which students feel more or less aligned with engineering while undergraduates.

\section{Literature review}

Expectancy-value theory (EVT) is a well-established, foundational framework that can be used to better understand factors contributing to persistence in engineering. Originally specific to adolescents in mathematics, EVT has since been proven to be reliable in the study of persistence and career interest among other populations of STEM students, including undergraduates (e.g., Eccles et al. 1990; Jones et al. 2010; Wang and Degol, 2013; Wigfield and Eccles, 2000).

The two central tenets of EVT are expectancy, more commonly referred to as self-efficacy, and subjective task values such as intrinsic, utility, and attainment values. Self-efficacy is an individual's belief in the ability to be successful at a task (Eccles and Wigfield, 2002). Intrinsic value, or expected enjoyment of engaging in the task (Eccles, 2005), is substantively aligned with interest as described in the STEM identity literature (e.g., Godwin, 2016), and will be referred to as such in this study. Utility value is defined as how well a task facilitates (i.e., how useful the task is to) an individual's current or long-range goals. Lastly, attainment value is the personal importance an individual places on doing well in a task (Wigfield and Eccles, 2000). Further, EVT also postulates the importance of several indirect factors, such as identity, that impact expectancies and values.

Here, we explore the literature surrounding these constructs in engineering, with respect to both gender and student division. While many scholars have researched these constructs, we focus specifically on the literature that examines these attitudes in undergraduate engineering, with additional emphasis on those studies that rely on longitudinal analyses and directly inform our research questions. These attitudes are often examined in combination with one another to the extent that we can discuss them individually, we do. 


\section{Self-efficacy}

Broadly speaking, there is substantial evidence of the importance of self-efficacy to educational persistence (e.g., Betz and Hackett, 1986; Eccles and Wigfield, 2002; Lent et al. 1984; Rottinghaus et al. 2003). There are various validated scales for assessing self-efficacy in engineering education, including those rooted in Bandura's (1997) work (e.g., Marra et al. 2009) and those developed using an identity framework (e.g., Godwin, 2016). Specific to engineering education, domain-specific self-efficacy has been found to be a significant predictor of engineering identity, and subsequently engineering career choice (Godwin et al. 2013).

More generally, research shows that self-efficacy is not only important in persistence for women but also that gender differences in self-efficacy contribute to the gendered academic and career outcomes in STEM (e.g., Brainard and Carlin, 1998; Lazarides and Lauermann, 2019; Stout et al. 2011; Wegemer and Eccles, 2019) and in engineering specifically (Marra et al. 2009). However, differences in engineering selfefficacy by gender are inconsistent across various studies. Men have frequently been found to have higher self-efficacy than women in engineering and in other STEM fields (Cheryan et al. 2017; Huang, 2013; Lent et al. 2018), but this is not always the case (Concannon and Barrow, 2009). In longitudinal analyses of first-year engineering students, men had higher engineering self-efficacy than women in one cross-section of the study, but not the other; yet both groups saw a decrease in self-efficacy over time (Jones et al. 2010). The results were also mixed in a study by Marra et al. (2009) in which the authors conducted a 6-year, multi-institutional longitudinal study of various measures of women's self-efficacy in engineering; there were increases in some measures of selfefficacy over time, but not in others.

There is little in regard to differences in selfefficacy based on students' year in program. This is not a surprise as the majority of research on student attitudes and educational outcomes in engineering education is focused on first-year students (e.g., Godwin and Kirn, 2020; Jones et al. 2010). In a cross-sectional study of engineering students across various years in their program, Concannon and Barrow (2009) examined two scales of engineering selfefficacy and found significant differences by students' year. The findings revealed 4th-year students had higher engineering self-efficacy than 5th-year students. Also using a cross-sectional design, Godwin and Lee (2017) found a significant difference in selfefficacy between first- and fourth-year students, where first-year students reported higher means.
In all, we see clear links between efficacious beliefs, persistence, and career choice in engineering; however, the literature does not outline a clear or consistent picture of whether, or how, self-efficacy differs by gender, student year or over time.

\section{Subjective task values}

Following EVT framework, several studies examine interest, utility value, and attainment value in combination with one another. Interest, which is the most frequently studied, has well-documented links to both academic and career outcomes across disciplines; in STEM specifically, there is a large gender gap in STEM interest during high school that is strongly associated with gender gaps in STEM higher education (Xie et al. 2015). Further, loss of interest has been well-cited as a core reason for leaving STEM disciplines, particularly among women (e.g., Blickenstaff, 2005; Riegle-Crumb et al. 2011; Sadler et al. 2012).

Few studies however examine changes in these values over time. In one such study of undergraduate engineering students, Matusovich et al. (2010) found engineering-related attainment value remained constant, interest increased, and utility value decreased over a 4-year period; attainment value was centrally important to other attitudinal beliefs and to students' persistence towards degree completion. However, in a study of first-year engineering students, Jones et al. (2010) found self-efficacy, interest, attainment value, and utility value all decreased from the fall to spring semester; the authors did not find significant differences in interest, attainment value, or utility value by gender. Interestingly, there was no change in career plans for these students over the same time period, suggesting that these beliefs may hold varying significance at different points along students' undergraduate careers, especially in their contribution towards post-graduation plans.

More recently, Robinson et al. (2019) found engineering students' self-efficacy, utility value, and attainment value decreased during the first 2 years of college. Yet, Godwin and Lee (2017) found no differences in interest by students' year using crosssectional analyses. Still, the analyses from that study generally affirm that first- and second-year students have similar attitudes to one another and third- and fourth-year students have similar attitudes to one another (Godwin and Lee, 2017), pointing to a lower and upper division dichotomy in undergraduate engineering students' attitudes. Thus, there are mixed conclusions to be drawn in regard to differences in values based on students' year in program.

In all, we see positive associations between beliefs such as interest, which is often lower for women, and 
persistence in engineering. However, the literature offers contradictory information about how these beliefs vary by student year or over time.

\section{Engineering identity}

Engineering identity, or how closely students see themselves aligned with their sense of what a professional engineer is, has received much attention in the recent literature, as evidenced by several recent literature reviews (e.g., Morelock, 2017; Patrick and Borrego, 2016; Rodriguez et al. 2018). The predominant model of engineering identity draws on science identity, as first developed in qualitative work by Carlone and Johnson (2007). Over the last decade, this framework has been further developed and used to examine self-efficacy, interest, and identity beliefs in various STEM domains such as physics (Hazari et al. 2010) and math (Cass et al. 2011; Cribbs et al. 2016). Notably, in engineering, it has recently been used to examine outcomes such as domain identification and career interest (Buontempo et al. 2017; Godwin and Lee, 2017; Patrick, Seepersad, et al. 2018; Prybutok et al. 2016).

Broadly speaking, gender has been cited as an important component of negotiating one's identity in engineering (e.g., Eccles, 2007; Faulkner, 2007, 2009; Hatmaker, 2013; Kyriakidou, 2011; Mcllwee and Robinson, 1992; Powell et al. 2009; Riegle-Crumb et al. 2012) and crosssectionally, women are found to have lower levels of engineering identity than men across educational stages (e.g., Buontempo et al. 2017; Meyers et al. 2012; Patrick et al. 2021).

Findings related to year in program again vary across and within methodologies. In a cross-sectional study, Meyers et al. (2012) identified differences in engineering identity by student division, where first-year students were less likely to identify themselves as engineers than all other students. Similarly, Godwin and Lee (2017) found significant differences in students' engineering identity by year in college, where fourth-year students reported the highest overall values of engineering identity. Yet, in a longitudinal study, Chachra et al. (2008) found gender differences in engineering identity among second-year students, but not first-year students. Similarly, Jones et al. (2010) found no change in engineering identity for first-year men or women over one semester. Given this extant literature, we understand that engineering identity is closely linked with other engineering attitudes and is often lower for women and lower division students. However, we do not have a clear picture of its development over time.

\section{Methods}

As part of a larger project (Patrick et al. 2017), we surveyed over 3000 undergraduate engineering students about their engineering attitudinal beliefs from the fall of 2016 to the spring of 2019. The online survey, which took approximately fifteen minutes to complete, was administered in class during the first 4 weeks of each semester. The targeted courses were required courses in each of the departments surveyed. Survey participants included students from the Civil, Biomedical, and Mechanical Engineering departments at one large, public institution. Students at this institution are admitted directly to their majors. A subset of this sample, including only students who took two surveys 1 year apart from one another (e.g., a survey from fall 2016 and a second survey from fall 2017), are used to address our research questions.

\section{Survey instrument}

The survey measured students' attitudinal beliefs related to engineering. During its 3-year administration, the survey evolved through several iterations. In all, the instrument captured information about 25 unique factors, several of which are explored in our prior work (e.g., Patrick et al. 2017). However, a core set of engineering attitudes were measured consistently at every time point, given their relationships to other academic and professional outcomes. These five variables are examined here: engineering attainment value, engineering utility value, engineering selfefficacy, engineering interest, and engineering identity. Survey items are summarized below and detailed in Appendix: Table 6.

Engineering attainment value and engineering utility value were taken from a subscale in early work with expectancy-value theory and modified from "math" to "engineering" (Wigfield and Eccles, 2000). All items were asked on a 5-point Likert scale, ranging from 1 "not at all" to 5 "very." To measure engineering attainment value, students were asked to rate how strongly they agreed that "for them, being good at engineering is important" and "compared to other activities, how important is it for them to be good at engineering?". This two-item scale has an alpha of 0.91 . Similarly, to measure engineering utility value, students were asked to rate "in general, how useful is what you learn in engineering?". This was a single item variable.

Engineering self-efficacy was measured by asking students the extent to which they agreed with a series of five statements about their capabilities in engineering (Patrick, Borrego, et al. 2018). These five items were measured on a 5-point Likert scale, ranging from "strongly disagree" to "strongly agree." This scale has an alpha of 0.86 . This scale derives from an identity framework of academic self-efficacy or an "individuals' 
self-concept and self-efficacy beliefs that are formed specifically toward academic (as distinct from nonacademic, general, social, emotional, or physical) domains" (Bong and Skaalvik, 2003, p. 6), rather than self-efficacy scales rooted in Bandura's (1997) work. This is a limitation of our instrument.

Similarly, to measure engineering interest, students were asked to rank the extent to which they agreed that they are "interested in learning more about engineering" and "enjoy learning engineering". These 2 items were also measured on a 5-point Likert scale, ranging from "strongly disagree" to "strongly agree." This scale has an alpha of 0.86 .

To measure engineering identity, we used the average of two survey items that asked students to rate: "To what extent does your own sense of who you are (i.e., your personal identity) overlap with your sense of what an engineer is (i.e., the identity of an engineer)?" (Borrego et al. 2018). Students first responded to this question on an 8-point Likert scale ranging from 1 "not at all" to 8 "to a great extent." Then, the question stem was repeated for a visual item with successively more overlapping Venn diagrams corresponding with eight Likert-style response ranging from 1 "far apart" to 8 "complete overlap." This scale has an alpha of 0.97 .

\section{Data analysis}

We conducted all data analyses using StataCorp. 2015, Stata Statistical Software: Release 17. Prior to analysis, survey responses were matched by students' university IDs. This matching process identified 495 unique participants who had completed surveys at timepoints 1 year apart from one another (e.g., fall 2016 and fall 2017). If students had completed the survey more than two times, we used the first pair of responses that were 1 year apart. Subsequently, we removed respondents by listwise deletion if they were missing values for any of the analytical variables at either timepoint, leaving an analytical sample of $n=278$. While this matching diminished our sample size, it is a stronger research design that ensures observed differences cannot be due to comparing different students taking the surveys (Welkowitz et al. 2006).

Student responses were then linked with demographic information (participants' gender, race/ethnicity, and academic classification) retrieved from university records following survey administration; this information was used to generate descriptive statistics for our sample. In this study, student division refers to lowerclassmen (freshmen and sophomores) and upperclassmen (juniors and seniors). Rather than generate student division from institutional records of credit hours completed (which makes students with advanced placement and transfer credits appear further along in their degree program), student division was generated from the course in which each student took the survey. The surveyed courses were along the main program of work for each department and could be linked to student year using degree plans and a designation in the institution's course catalog.

After noting gaps in the extant literature on these constructs with respect to both gender and student division and differences between our preliminary longitudinal analyses and trends in the literature, we decided to conduct both cross-sectional and longitudinal analyses. Our analyses examine differences by gender and student division for each of the five variables on our sample of $n=278$. Here, we treat each method as a standalone study and follow the procedures appropriate to each set of analyses. Finally, we compare results between methods.

\section{Method A: cross-sectional analysis}

To begin to answer our research questions, we conducted cross-sectional analyses of students' attitudinal beliefs at the first survey timepoint $(n=278)$. We looked for differences across student groups for each of the five variables by using a two-way multivariate analysis of variance (ANOVA) with gender and student division. Analyses were only conducted at the first survey timepoint; if this were truly a cross-sectional study, we would only have students' first response to the survey. As appropriate, follow-up one-way ANOVAs were used to identify which individual variables varied with respect to the student group(s) that showed statistical significance at the model level. We used a Bonferroni correction of $p$ $<0.0083$ to account for the six total ANOVAs conducted.

\section{Method B: longitudinal analysis}

Subsequently, we conducted longitudinal analyses on our larger dataset with matched student survey responses 1 year apart from one another $(n=278)$. To do so, we conducted repeated measures ANOVAs (RMANOVA) for each of the five variables. Here, the data file was split by student division to allow analysis across all three dimensions of our longitudinal dataset (time, student division, gender), given the evidence of variation by each of these dimensions in the literature and significant differences by student division highlighted in our cross-sectional analysis. Each RMANOVA tests for the effect of time, the effect of gender, and a potential interactional effect of time and gender. Since no interactions were ever found to be significant in our analysis, we do not detail those 
results here. This matched, longitudinal design ensures observed differences cannot be due to different students taking the surveys.

We conducted a total of 10 repeated measures ANOVAs with time and gender: five for lower division students and five for upper division students. We used an omnibus F-test, with a Bonferroni correction of $p<0.005$, to determine model significance for each of the 10 RMANOVAs. This method requires the $F$-statistic of the overall model to be significant before allowing examination of the significance of main and interactional effects, thereby reducing type I error associated with multiple comparisons (Fletcher et al. 1989). To further account for familywise error within each model (Cramer et al. 2016), we used a Bonferroni correction of $p<0.0167$ to account for the three comparisons (two main effects and one interaction) generated within each model. This tiered approach conservatively safeguards against type I error, without overinflating the type II error associated with a Bonferroni correction of $p<$ 0.001 for all 30 comparisons.

\section{Results}

Table 1 lists the demographic and academic overview of the analytical sample, generated from university administrative records. The table is disaggregated by gender, where $53 \%$ of the total sample is male and $47 \%$ is female.

Compared to national statistics on engineering degree attainment, our sample shows an

Table 1 Demographic and academic overview of the analytical sample, $n=278$

\begin{tabular}{|c|c|c|c|c|c|c|}
\hline & \multicolumn{2}{|l|}{ Men } & \multirow{2}{*}{$\begin{array}{l}\text { Women } \\
n=132\end{array}$} & \multicolumn{3}{|c|}{ Total } \\
\hline & $n=146$ & $\%$ & & $\%$ & $n=278$ & $\%$ \\
\hline \multicolumn{7}{|l|}{ Engineering major } \\
\hline Biomedical & 54 & 37.0 & 65 & 49.2 & 119 & 42.8 \\
\hline Civil & 47 & 32.2 & 45 & 34.1 & 92 & 33.1 \\
\hline Mechanical & 45 & 30.8 & 22 & 16.7 & 67 & 24.1 \\
\hline \multicolumn{7}{|l|}{ Student classification } \\
\hline Lower division & 90 & 61.6 & 73 & 55.3 & 163 & 58.6 \\
\hline Upper division & 56 & 38.3 & 59 & 44.7 & 115 & 41.4 \\
\hline \multicolumn{7}{|l|}{ Race/ethnicity } \\
\hline White only & 63 & 43.5 & 65 & 49.2 & 128 & 46.2 \\
\hline Asian only & 41 & 28.3 & 36 & 27.3 & 77 & 27.8 \\
\hline Hispanic or Latino & 32 & 22.1 & 22 & 16.7 & 54 & 19.5 \\
\hline Multiracial & 5 & 3.5 & 6 & 4.6 & 11 & 4.0 \\
\hline Foreign & 4 & 2.76 & 2 & 1.5 & 6 & 2.2 \\
\hline Black only & 0 & 0.0 & 1 & 0.4 & 1 & 0.4 \\
\hline Prefer not to answer & 1 & 0.4 & 0 & 0.0 & 1 & 0.4 \\
\hline
\end{tabular}

overrepresentation of students who identify as women, Asian, and Hispanic or Latino, and underrepresentation of all other student groups (National Science Foundation and National Center for Science and Engineering Statistics, 2019). However, the enrollment profiles of the departments surveyed show that the Biomedical, Civil, and Mechanical engineering departments are $51 \%, 45 \%$, and $21 \%$ female (an average of $39 \%$ ), respectively (American Society for Engineering Education, 2017). Similarly, these targeted departments are $42 \%, 43 \%$, and $56 \%$ (an average of $47 \%$ ) White; $44 \%, 17 \%$, and 19\% (an average of 27\%) Asian; and $6 \%, 27 \%$, and $16 \%$ (an average of 16\%) Hispanic or Latino (American Society for Engineering Education, 2017). Thus, the sample only shows an overrepresentation of women with respect to the departments in which data was collected.

\section{Method A: cross-sectional analyses}

To begin to answer our research questions, we conducted a two-way multivariate ANOVA to test for differences in the means of the five variables by gender and student division at timepoint 1. Given the cross-sectional analysis design, any differences by division would be interpreted as changes over time as a student progresses through a degree program. Analyses revealed no significant difference by gender, but a significant difference by student division $(F(1$, $275)=6.35, p<0.001)$. Follow-up one-way ANOVAs were used to identify significant differences by classification per variable. Table 2 details the means and standard deviations for each variable by division, as well as the corresponding effect sizes (i.e., standardized mean difference). Following Cohen (2013), effect sizes from 0 to 0.25 indicate a small difference, effect sizes from 0.25 to 0.40 indicate a moderate difference, and effect sizes above 0.40 indicate a large difference.

Analyses revealed two statistically significant effects of student division: engineering utility value $(F(1,276)$ $=15.59, p=0.0001)$ and engineering interest $(F(1$, $276)=22.23, p=0.0000$ ). For all variables, lower division students reported higher means than upper division students. The differences in engineering interest and engineering utility value were small at 0.07 and 0.05 standard deviations, respectively. Analyses did not reveal any statistically significant differences by gender for these variables.

\section{Method B: longitudinal analyses}

Next, we conducted two sets of repeated measures ANOVAs to assess gender differences in each of the five analytical variables over a 1-year time period for lower and upper division students. These results are 
Table 2 One-way ANOVAs by student division, $n=278$

\begin{tabular}{|c|c|c|c|c|c|}
\hline \multirow[t]{2}{*}{ Factor } & \multicolumn{2}{|l|}{ Mean (s.d.) } & \multirow{2}{*}{$\begin{array}{l}F- \\
\text { stat }\end{array}$} & \multirow{2}{*}{$\begin{array}{l}p \\
\text { value }\end{array}$} & \multirow{2}{*}{$\begin{array}{l}\text { Effect } \\
\text { size }\end{array}$} \\
\hline & Lower, $n=163$ & Upper, $n=115$ & & & \\
\hline Attainment value & $4.52(0.60)$ & $4.31(0.80)$ & 6.58 & 0.0108 & 0.02 \\
\hline Utility value & $4.39(0.71)$ & $4.01(0.85)$ & 15.59 & $0.0001^{*}$ & 0.05 \\
\hline Self-efficacy & $4.01(0.58)$ & $3.94(0.72)$ & 0.75 & 0.3867 & 0.00 \\
\hline Interest & $4.54(0.57)$ & $4.12(0.91)$ & 22.23 & $0.0000^{*}$ & 0.07 \\
\hline Identity $^{1}$ & $5.11(1.27)$ & $4.83(1.19)$ & 3.44 & 0.0646 & 0.01 \\
\hline
\end{tabular}

*An asterisk indicates statistical significance at $p=0.0083$

${ }^{1}$ Indicates a response scale of $1-8$. All others are $1-5$

summarized in Table 3, where a "Y" indicates that a significant effect was found at $p<0.005$, adjusting for the 10 omnibus $F$-tests conducted. For ease of comparison, the significant findings from cross-sectional analyses (Table 2) are included in the far-right columns.

Analyses on lower division students revealed statistically significant effects of time for three variables and no effects of gender. For upper division students, repeated measures ANOVAs revealed a statistically significant effect of time on attainment value and an effect of gender on self-efficacy. We tested for interactions between time and gender, but none were significant. These results are detailed in the following sections.

\section{Time}

Table 4 shows the effects of time for lower and upper division students including Cohen's $d$ effect size. Analyses revealed three statistically significant effects of time for lower division students: engineering utility value $(F(1,161)=14.18, p=0.0002)$, engineering selfefficacy $(F(1,161)=7.61, p=0.0065)$, and engineering interest $(F(1,161)=31.40, p=0.0000)$. The ratings of all three variables decreased significantly over time. The change in engineering interest, engineering utility value, and engineering self-efficacy were large to moderate at $0.45,0.38$, and 0.26 standard deviations, respectively.

Repeated measures ANOVAS for upper division students revealed only one statistically significant effect of time for engineering attainment value $(F(1,113)=11.12$, $p=0.0012$ ). Students' ratings of engineering attainment value decreased statistically significantly over time, but the effect was small at only 0.24 standard deviations. Analyses did not reveal any significant effects of time for the remaining attitudinal variables for upper division students.

\section{Gender}

Table 5 details the effect of gender for each of the five variables for lower and upper division students, as well as the Cohen's $d$ effect size for each variable.

Repeated measure ANOVAs revealed no statistically significant effects of gender for lower division students. Analyses further revealed only one statistically significant effect of gender for upper division students: engineering self-efficacy $(F(1,113)=6.43, p=0.0126)$. The effect size, 0.41 standard deviations, indicates a large gender difference for upper division students, where male students have statistically significantly higher self-efficacy than their female peers.

Table 3 Summary of significant results from RMANOVA and ANOVAs

\begin{tabular}{|c|c|c|c|c|c|c|}
\hline \multirow[t]{3}{*}{ Factor } & \multicolumn{4}{|c|}{ Longitudinal } & \multirow{2}{*}{\multicolumn{2}{|c|}{$\begin{array}{l}\text { Cross-sectional } \\
\text { All, } \\
n=278\end{array}$}} \\
\hline & \multicolumn{2}{|c|}{$\begin{array}{l}\text { Lower division, } \\
n=163\end{array}$} & \multicolumn{2}{|c|}{$\begin{array}{l}\text { Upper division, } \\
n=115\end{array}$} & & \\
\hline & Time & Gender & Time & Gender & Division (comparable to time) & Gender \\
\hline Attainment value & - & - & $\mathrm{Y}$ & - & - & - \\
\hline Utility value & Y & - & - & - & Y & - \\
\hline Self-efficacy & Y & - & - & Y & - & - \\
\hline Interest & Y & - & - & - & Y & - \\
\hline Identity & - & - & - & - & - & - \\
\hline
\end{tabular}


Table 4 Effects of time for lower and upper division students from RMANOVAs

\begin{tabular}{|c|c|c|c|c|c|c|c|c|}
\hline \multirow{3}{*}{$\begin{array}{l}\text { Engineering } \\
\text { attitudinal } \\
\text { beliefs }\end{array}$} & \multicolumn{4}{|c|}{ Lower, $n=163$} & \multicolumn{4}{|c|}{ Upper, $n=115$} \\
\hline & \multicolumn{2}{|l|}{ Mean (s.d.) } & \multirow[t]{2}{*}{ Difference } & \multirow{2}{*}{$\begin{array}{l}\text { Effect } \\
\text { size }\end{array}$} & \multicolumn{2}{|c|}{ Mean (s.d.) } & \multirow[t]{2}{*}{ Difference } & \multirow{2}{*}{$\begin{array}{l}\text { Effect } \\
\text { size }\end{array}$} \\
\hline & Pre & Post & & & Pre & Post & & \\
\hline Attainment value & $4.52(0.61)$ & $4.43(0.84)$ & -0.09 & 0.12 & $4.31(0.80)$ & $4.10(0.96)$ & $-0.21^{*}$ & 0.24 \\
\hline Utility value & $4.39(0.71)$ & $4.09(0.87)$ & $-0.30^{*}$ & 0.38 & $4.02(0.85)$ & $3.89(0.88)$ & -0.13 & 0.15 \\
\hline Self-efficacy & $4.01(0.58)$ & $3.85(0.65)$ & $-0.16^{*}$ & 0.26 & $3.94(0.72)$ & $3.88(0.72)$ & -0.06 & 0.08 \\
\hline Interest & $4.54(0.57)$ & $4.24(0.74)$ & $-0.30^{*}$ & 0.45 & $4.12(0.91)$ & $4.16(0.88)$ & +0.04 & 0.04 \\
\hline Identity $^{1}$ & $5.11(1.27)$ & $5.02(1.30)$ & -0.09 & 0.07 & $4.83(1.19)$ & $4.96(1.37)$ & +0.13 & 0.10 \\
\hline
\end{tabular}

*Statistical significance at $p<=0.0167$

${ }^{1}$ Scale of $1-8$. All others on a scale of $1-5$

\section{Discussion}

In this study, we sought to better understand students' engineering attitudinal beliefs with respect to time, student division, and gender. Our findings make several contributions to the literature. First, by comparing results from both cross-sectional and longitudinal analyses of identical variables within the same data set, we highlight how researchers may draw inaccurate conclusions from weaker study designs; this implies that our current understanding of these engineering attitudes (based largely on cross-sectional work) is incomplete. We hope these results lend clarity to discrepancies in the literature across methodological approaches, as well as suggest methods and variables to be explored in future studies. Second, we explored attitudinal differences by student division not previously documented in the literature. For this discussion, we first summarize and compare findings across analyses, and then review implications by attitudinal belief.

\section{Comparisons across methods}

Our first research question asked about differences in engineering attitudinal beliefs by division and gender, identified using cross-sectional and longitudinal analyses. Table 3 summarizes these results and provides a side-by-side comparison of which differences were identified by each method. Our second research question is concerned with inconsistencies in findings between cross-sectional and longitudinal analyses of the same dataset. If we were to only examine this dataset cross-sectionally, we would conclude that there are small differences in engineering utility value and engineering interest by student division, in which lower division students have higher means for both.

However, longitudinal analyses, which are a stronger research design (National Research Council, 2012), revealed statistically significant decreases in engineering utility value, engineering self-efficacy, and engineering interest for lower division students and significant

Table 5 Effects of gender for lower and upper division students from RMANOVAs

\begin{tabular}{|c|c|c|c|c|c|c|c|c|}
\hline \multirow{4}{*}{$\begin{array}{l}\text { Engineering } \\
\text { attitudinal } \\
\text { beliefs }\end{array}$} & \multicolumn{4}{|c|}{ Lower, $n=163$} & \multicolumn{4}{|c|}{ Upper, $n=115$} \\
\hline & \multicolumn{2}{|c|}{ Mean (s.d.) } & \multirow[t]{3}{*}{ Difference } & \multirow{3}{*}{$\begin{array}{l}\text { Effect } \\
\text { size }\end{array}$} & \multicolumn{2}{|c|}{ Mean (s.d.) } & \multirow[t]{3}{*}{ Difference } & \multirow{3}{*}{$\begin{array}{l}\text { Effect } \\
\text { size }\end{array}$} \\
\hline & Men & Women & & & Men & Women & & \\
\hline & $n=90$ & $n=73$ & & & $n=56$ & $n=59$ & & \\
\hline Attainment value & $\begin{array}{l}4.44 \\
(0.75)\end{array}$ & $\begin{array}{l}4.52 \\
(0.70)\end{array}$ & 0.12 & 0.11 & $\begin{array}{l}4.09 \\
(0.90)\end{array}$ & $\begin{array}{l}4.31 \\
(0.64)\end{array}$ & 0.22 & 0.28 \\
\hline Utility value & $\begin{array}{l}4.28 \\
(0.78)\end{array}$ & $\begin{array}{l}4.19 \\
(0.83)\end{array}$ & 0.09 & 0.11 & $\begin{array}{l}3.94 \\
(0.90)\end{array}$ & $\begin{array}{l}3.97 \\
(0.83)\end{array}$ & 0.03 & 0.03 \\
\hline Self-efficacy & $\begin{array}{l}3.95 \\
(0.60)\end{array}$ & $\begin{array}{l}3.90 \\
(0.65)\end{array}$ & 0.05 & 0.08 & $\begin{array}{l}4.06 \\
(0.72)\end{array}$ & $\begin{array}{l}3.77 \\
(0.70)\end{array}$ & $0.29^{*}$ & 0.41 \\
\hline Interest & $\begin{array}{l}4.41 \\
(0.65)\end{array}$ & $\begin{array}{l}4.37 \\
(0.72)\end{array}$ & 0.04 & 0.06 & $\begin{array}{l}4.21 \\
(0.91)\end{array}$ & $\begin{array}{l}4.07 \\
(0.88)\end{array}$ & 0.14 & 0.16 \\
\hline Identity & $\begin{array}{l}5.21 \\
(1.34)\end{array}$ & $\begin{array}{l}4.88 \\
(1.19)\end{array}$ & 0.33 & 0.27 & $\begin{array}{l}4.92 \\
(1.37)\end{array}$ & $\begin{array}{l}4.86 \\
(1.21)\end{array}$ & 0.06 & 0.05 \\
\hline
\end{tabular}

*Statistical significance at $p<=0.0167$

${ }^{1}$ Scale of $1-8$. All others on a scale of $1-5$ 
decreases in engineering attainment value for upper division students over a 1-year period. These discrepancies in findings show variation in engineering attitudinal beliefs that are obscured when the dataset is only examined cross-sectionally. We consider the longitudinal research design to be the stronger of the two because it utilizes twice as much data (i.e., a second time point) and compares students against themselves, meaning observed differences cannot be due to comparing different students taking the surveys (Welkowitz et al. 2006). We compare our results for each attitudinal belief with the findings of prior studies in the sections below.

Our analyses demonstrate that several of the attitudes important to retention decrease over time, even for students who persist in their engineering baccalaureate programs. It stands to reason that students with the biggest decreases in those attitudes over time would not persist to be included as upper division students in cross-sectional studies. This attrition has the effect of underestimating the decreases in attitudes as students progress through engineering undergraduate programs. Thus, our results are consistent with the explanation that crosssectional studies of undergraduate engineers are biased in that upper division students are sorted for particularly high attitudes that are in many cases not statistically significantly different from those of lower division students. While we would like to think that successful experiences and knowledge gains would translate to more positive attitudes toward engineering for upper division students, it may be more accurate to conclude that many aspects of the engineering undergraduate climate take a toll on the engineering attitudes of students.

Simply put, these beliefs change within students over time, and a cross-sectional research design, which shows variation between students with respect to students' academic and demographic characteristics, is unable to capture the overall downward trend in attitudinal beliefs within students. Further, longitudinal analyses revealed a gender gap in engineering self-efficacy for upper division students, where men reported higher means than women. In contrast, cross-sectional analyses did not find gender differences. While we acknowledge that cross-sectional research is more convenient and practical, as a whole, our results suggest important trends are being missed by cross-sectional analyses.

\section{Differences over time (longitudinal results)}

Over a 1-year period, lower division students experienced significant losses in engineering interest, engineering utility value, and engineering self-efficacy, and upper division students reported significant losses in engineering attainment value. This finding echoes prior work, which found decreased interest, utility value, and self-efficacy in first-year students; however, Jones et al. (2010) also reported decreases in attainment value. These losses reported in this study are noteworthy, as domain-specific interest, value, and self-efficacy have been previously linked to retention, persistence, and career choices in engineering (Godwin et al. 2013; Matusovich et al. 2010; Patrick, Borrego, et al. 2018).

Overall, lower division students exhibited more fluctuation in their attitudinal beliefs and career intentions than their upper division counterparts, who only reported a significant loss in engineering attainment value. To our knowledge, there is not a longitudinal analysis of these constructs that also speaks to differences by student division. However, the divide between these findings may be attributable again to the difference in research design, if cross-sections of upperclassmen include only students who have persisted thus far in the degree program-something which may actually be an effect of their engineering attitudes. Readers are reminded that $20 \%$ of undergraduates leave engineering within the first few semesters (Yoder, 2017).

\section{Self-efficacy}

Lower division students' academic self-efficacy, or confidence in their ability to complete academic engineering tasks, decreased over a 1-year time period. This change is not surprising, as engineering selfefficacy beliefs have been proven to be malleable (e.g., Mamaril and Royal, 2008). Yet, the losses in selfefficacy reported by upper division students were not statistically significant. These results may simply imply that when students initially enter an engineering degree program, they are not yet aware of what they do not know, and therefore a drop in selfefficacy may be expected. Yet, given the association between self-efficacy and outcomes such as persistence in engineering, this loss in self-efficacy is still notable. The literature has identified several factors known to impact self-efficacy development. For instance, mastery experiences like course projects or internships are commonly cited as an important source of self-efficacy beliefs (Bandura, 1997; Mamaril and Royal, 2008; Marra et al. 2009); it is likely that upper division students have had more exposure and access to these types of experiences (e.g., internships), which may have reaffirmed their confidence in their engineering capabilities. As such, interventions focused on building self-efficacy for lower division students specifically could be important to counteract the 
decreases demonstrated here, and subsequently, increase likelihood of persistence along an engineering career pathway (Godwin et al. 2013). Additional research into longitudinal self-efficacy patterns should explore these beliefs in relation to experiences throughout undergraduate engineering.

Further, longitudinal analyses showed a gender gap in engineering self-efficacy for upper division students, where men reported higher means than women. This result is consistent with prior research that has found that women report lower levels of engineering self-efficacy than men across educational stages (Cheryan et al. 2017; Huang, 2013; Lent et al. 2018), which in turn contributes to gendered academic and career outcomes in STEM (e.g., Brainard and Carlin, 1998; Godwin et al. 2013; Lazarides and Lauermann, 2019; Wegemer and Eccles, 2019) and in engineering specifically (Marra et al. 2009). In contrast, cross-sectional analyses did not find such a gender difference which further reinforces the importance of longitudinal analyses.

It is noteworthy to recall, first, that the gender gap in engineering self-efficacy was consistent across time for upper division students, which implies that these students' experiences throughout the 1-year time period did not influence their perceptions of their academic capabilities, but rather simply maintained the status quo of gendered differences in this construct. Second, this gender gap did not exist for the lower division students, which may suggest that women in engineering are disproportionately losing efficaciousness while undergraduates. Similar to our recommendations for lower division students, interventions focused on building self-efficacy for women specifically could be important to increase likelihood of persistence (Marra et al. 2009).

\section{Subjective task values}

Our results echo extant literature documenting losses in particular expectancy and value-related beliefs among engineering students (Jones et al. 2010; Matusovich et al. 2010; Robinson et al. 2019). Analyses did not reveal any gender differences for students of any level across these three constructs; this is consistent with prior literature that identified decreases in these beliefs over one semester, but no gender difference (Jones et al. 2010).

Over a 1-year period, lower division students experienced significant losses in engineering interest and engineering utility value. This partially contradicts findings from Matusovich et al. (2010), where interest increased and utility values decreased over a 4-year period. Significant losses in interest are particularly troubling given their documented links to persistence, such as 1-year persistence in the major (Patrick, Borrego, et al. 2018) and intention to pursue postgraduation plans in engineering (Sheppard et al. 2014). Recalling the survey items used to measure this construct, losses in engineering utility value may indicate that students do not see what they learn in engineering as being useful to them.

Similarly, upper division students reported significant losses in engineering attainment value, perhaps meaning the importance of being good at engineering decreased for them over time; unfortunately, prior longitudinal analyses of engineering attainment value have focused only on lower division students. However, decreases in attainment value could foreshadow subsequent decreases in other attitudinal beliefs, given the important relationship between attainment value and both interest and utility value (Matusovich et al. 2010).

These losses in student motivation, not unsurprisingly, suggest that these students will be less likely to continue persisting along an engineering pathway (Marra et al. 2009; Patrick, Borrego, et al. 2018). However, it may be that students can experience decreases in these beliefs and still persist with engineering undergraduate degree programs. This may reflect other factors (such as stereotype beliefs) that need to be examined with respect to retention, or a disconnect between students' intent to graduate and their post-graduation plans. Future quantitative research on persistence would be better informed through an understanding of how specific factors fluctuate within students as they traverse the entirety of their undergraduate careers, especially given the differences by student division identified here.

\section{Engineering identity}

Engineering identity showed no statistically significant difference across a 1-year time period. This result suggests that identity is a more stable construct within engineering undergraduate students, as shown longitudinally in Jones et al. (2010). There is little longitudinal work examining engineering identity. However, this result is consistent with some prior cross-sectional literature, such as Prybutok et al. (2016), who found no difference in the engineering identity of lower and upper division students. Yet, another cross-sectional study found engineering identity was highest among fourthyear students (Godwin and Lee, 2017); while this may suggest this construct increases throughout undergraduate experiences, results from our matched longitudinal design suggests this is not the case. Instead, it is possible that students with the lowest identities leave engineering before reaching their fourth year, thus overinflating the mean for fourth-year students. As theorized by Eccles' and colleagues, there are a variety of social psychological 
and contextual influences on the formation of students' beliefs, such as pre-college factors or institutional contexts. Nonetheless, further examination of attitudinal variables is warranted as there were clear changes in attitudes over time that have been cited as important to retention and persistence in engineering.

\section{Implications}

Prior work focusing on first-year engineering students has uncovered many important attitudinal belief changes that have led to interventions which have improved retention rates in engineering. This study illustrates that some of the attitudinal beliefs shown to decline in the first year actually continue to decline as students progress through an engineering undergraduate program. This result suggests that some of the important messaging and retention efforts focused at K-12 and first-year levels need to continue into upper division curricula. For example, more attention should be paid to the types of design problems, problem contexts and examples, and exposure to professional engineers, to continue to send messages about how engineering helps society. Connecting assignments to students' personal goals and identities as well as exposure to role models who value academic and professional attainment remain important for upper division students whose attainment value decreased over time in this study. Similarly, self-efficacy-building experiences in projects, research or internships, as well as vicarious experiences through role models (Bandura, 1997; Mamaril and Royal, 2008; Marra et al. 2009) remain important for upper division women students whose selfefficacy gaps (as compared with men) were evident in this study.

\section{Limitations}

We note a few limitations to this study. Data collection took place at one institution from students in three engineering disciplines; institutional and departmental characteristics specific to this university could account for some variance in our dataset and limit the generalizability of our study. For instance, our sample shows an overrepresentation of students who identify as women, Asian, and Hispanic or Latino, and an underrepresentation of all other student groups compared to national statistics on engineering degree attainment (National Science Foundation and National Center for Science and Engineering Statistics, 2019).

Additionally, there are a variety of factors not captured by our survey instrument that could contribute to variation in student responses (e.g., other relevant social identities). Similarly, the instrument itself existed in multiple versions throughout its 3-year administration; longitudinal analyses were limited to those factors that were held consistent. Further, in retrospect, the measurement of these constructs could have been more robust (e.g., utility value is indicated by one item). In particular, our self-efficacy scale focused on academic self-efficacy (deriving from identity studies) as compared to some of the other self-efficacy studies we cite (deriving from Bandura's work). While comparisons between studies can be limited by differences in survey items measuring these engineering attitudes, doing so demonstrates what may be missing in cross-sectional approaches. As such, we affirm the contribution of these results over prior work examining these constructs, given our larger sample size and stronger research design.

\section{Conclusion}

This study explored the relationships between undergraduate students' engineering attitudinal beliefs, gender, time, and student division. By comparing results from both cross-sectional and longitudinal analyses of identical variables, we highlight longitudinal variation in engineering attitudinal beliefs that are obscured when data is only examined crosssectionally. These findings underscore the importance of longitudinal analyses, especially when examining attitudinal beliefs, which are known to fluctuate over time and have been directly linked to academic outcomes. Our longitudinal results provide additional understanding about constructs that we know are both important to persistence and actionable for informing interventions.

Longitudinal analyses revealed an overall downward trend within students for all beliefs that changed significantly, showing that students lose enthusiasm for engineering. Moreover, lower division students exhibited more fluctuation in their attitudinal beliefs than their upper division counterparts. These losses may foreshadow attrition out of engineering for these students, whether during undergraduate education or further along the career pathway. Future quantitative research on persistence would be better informed through an understanding of how specific factors fluctuate within students as they traverse the entirety of their undergraduate careers. However, these findings provide an opportunity to introduce targeted interventions to build engineering utility value, engineering self-efficacy, and engineering interest for student groups whose means were lower than average. Doing so could subsequently improve retention rates and diversity in undergraduate engineering. 


\section{Appendix}

Table 6 Survey variables by item

\begin{tabular}{|c|c|c|c|}
\hline Factor & Question stem & Range & Items \\
\hline $\begin{array}{l}\text { Attainment } \\
\text { value }\end{array}$ & $\begin{array}{l}\text { Please answer the following questions about } \\
\text { engineering. }\end{array}$ & $1-5$ & $\begin{array}{l}\text { Compared to other activities, how important is it for you to be good at } \\
\text { engineering? } \\
\text { For me, being good in engineering is important. }\end{array}$ \\
\hline Utility value & $\begin{array}{l}\text { Please answer the following questions about } \\
\text { engineering. }\end{array}$ & $1-5$ & In general, how useful is what you learn in engineering? \\
\hline Self-efficacy & $\begin{array}{l}\text { To what extent do you disagree or agree } \\
\text { with the following statement? }\end{array}$ & $1-5$ & $\begin{array}{l}\text { I am confident that I can understand engineering outside of class. } \\
\text { I can overcome setbacks in engineering. } \\
\text { I am confident that I can understand engineering in class. } \\
\text { I can understand concepts I have studied in engineering. } \\
\text { I can do well on exams in engineering. }\end{array}$ \\
\hline Interest & $\begin{array}{l}\text { To what extent do you disagree or agree } \\
\text { with the following statement? }\end{array}$ & $1-5$ & $\begin{array}{l}\text { I am interested in learning more about engineering. } \\
\text { I enjoy learning engineering. }\end{array}$ \\
\hline Identity & $\begin{array}{l}\text { Please describe your relationship with } \\
\text { engineering by using the following } \\
\text { diagrams. }\end{array}$ & $1-8$ & $\begin{array}{l}\text { Which diagram best describes the level of overlap between your own identity } \\
\text { and the identity of an engineer? } \\
\text { To what extent does your own sense of who you are (i.e., your personal } \\
\text { identity) overlap with your sense of what an engineer is (i.e., the identity of an } \\
\text { engineer)? }\end{array}$ \\
\hline
\end{tabular}

\section{Abbreviations}

STEM: Science, Technology, Engineering and Mathematics; EVT: Expectancyvalue theory; ANOVA: Analysis of variance; RMANOVA: Repeated measures analysis of variance

\section{Acknowledgements}

We would like to thank our collaborators and the National Science Foundation for funding this project. Additionally, we thank the survey participants who made it possible to conduct this research.

\section{Authors' contributions}

Maura Borrego and Anita Patrick developed the survey instrument. Anita Patrick and Madison Andrews administered the survey. Madison Andrews conducted the data analysis and was the primary manuscript writer. All authors contributed to manuscript writing, and have read and approved the final manuscript.

\section{Funding}

This research is part of the Engineering Identity, its Predictors, and its Impact on Retention

across Educational Stages project funded by the National Science Foundation (1636449). Any opinions, findings, and conclusions in this article are the authors' and do not necessarily reflect the views of the National Science Foundation

\section{Availability of data and materials}

The datasets generated during and analyzed during the current study are not publicly available due to small sample size from many disciplines, genders, and racial groups but are available from the corresponding author on reasonable request.

\section{Competing interests}

The authors declare that they have no competing interests.

Received: 23 July 2020 Accepted: 28 December 2020

Published online: 09 March 2021

\section{References}

American Society for Engineering Education. (2017). Profiles of Engineering \& Engineering Technology Colleges. https://www.asee.org/papers-andpublications/publications/college-profiles. Accessed 3 Nov 2020 Bandura, A. (1997). Self-efficacy: The Exercise of Control. Macmillan.
Betz, N. E., \& Hackett, G. (1986). Applications of self-efficacy theory to understanding career choice behavior. Journal of social and clinical psychology, 4(3), 279-289.

Blackburn, H. (2017). The status of women in STEM in higher education: a review of the literature 2007-2017. Science \& Technology Libraries, 36(3), 235-273.

Blickenstaff, J. C. (2005). Women and science careers: leaky pipeline or gender filter? Gender and education, 17(4), 369-386.

Bong, M., \& Skaalvik, E. M. (2003). Academic self-concept and self-efficacy: How different are they really? Educational Psychology Review, 15(1), 1-40.

Borrego, M., Patrick, A. D., Martins, L., \& Kendall, M. (2018). A new scale for measuring engineering identity in undergraduates American Society for Engineering Education Gulf-Southwest Section Annual Meeting. Austin: TX.

Brainard, S. G., \& Carlin, L. (1998). A six-year longitudinal study of undergraduate women in engineering and science. Journal of Engineering Education, 87(4), 369-375.

Buontempo, J., Riegle-Crumb, C., Patrick, A. D., \& Peng, M. (2017). Examining Gender Differences in Engineering Identity among High School Engineering Students. Journal of Women and Minorities in Science and Engineering, 23(3), 271-287.

Carlone, H. B., \& Johnson, A. (2007). Understanding the science experiences of successful women of color: Science identity as an analytic lens. Journal of Research in Science Teaching, 44(8), 1187-1218. https://doi.org/https://doi.org/ 10.1002/tea.20237

Cass, C. A. P., Hazari, Z., Cribbs, J., Sadler, P. M., \& Sonnert, G. (2011). Examining the impact of mathematics identity on the choice of engineering careers for male and female students Frontiers in Education Conference Rapid City, SD. <Go to |S|>://WOS:000300879800186

Chachra, D., Kilgore, D., Loshbaugh, H., McCain, J., \& Chen, H. (2008). Being and becoming: gender and identity formation of engineering students. Pittsburgh, PA: Research Brief. American Society for Engineering Education Annual Conference.

Cheryan, S., Ziegler, S. A., Montoya, A. K., \& Jiang, L. (2017). Why are some STEM fields more gender balanced than others? Psychological Bulletin, 143(1), 1-35.

Cohen, J. (2013). Statistical power analysis for the behavioral sciences (2nd ed.). New York: Academic Press.

Concannon, J. P., \& Barrow, L. H. (2009). A cross-sectional study of engineering students' self-efficacy by gender, ethnicity, year, and transfer status. Journal of Science Education and Technology, 18(2), 163-172.

Cramer, A. O., van Ravenzwaaij, D., Matzke, D., Steingroever, H., Wetzels, R., Grasman, R. P., ... Wagenmakers, E.-J. (2016). Hidden multiplicity in exploratory multiway ANOVA: Prevalence and remedies. Psychonomic bulletin \& review, 23(2), 640-647.

Cribbs, J., Cass, C. A. P., Hazari, Z., Sadler, P. M., \& Sonnert, G. (2016). Mathematics identity and student persistence in engineering. International Journal of Engineering Education, 32 (1(A)), 163-171. 
Eccles, J. S. (2005). Subjective task value and the Eccles et al. model of achievement-related choices. Handbook of competence and motivation, 105121.

Eccles, J. S. (2007). Where are all the women? gender differences in participation in physical science and engineering. In S. J. Ceci \& W. M. Williams (Eds.), Why aren't more women in science?: Top researchers debate the evidence (pp. 199210). Washington, D.C: American Psychological Association.

Eccles, J. S., Jacobs, J. E., \& Harold, R. D. (1990). Gender role stereotypes, expectancy effects, and parents' socialization of gender differences. Journal of social issues, 46(2), 183-201.

Eccles, J. S., \& Wigfield, A. (2002). Motivational beliefs, values, and goals. Annual review of psychology, 53(1), 109-132.

Faulkner, W. (2007). Nuts and Bolts and People' Gender-Troubled Engineering Identities. Social studies of science, 37(3), 331-356.

Faulkner, W. (2009). Doing gender in engineering workplace cultures. I. Observations from the field. Engineering Studies, 1(1), 3-18.

Fletcher, H. J., Daw, H., \& Young, J. (1989). Controlling multiple F test errors with an overall $F$ test. The Journal of applied behavioral science, 25(1), 101-108.

Godwin, A. (2016). The development of a measure of engineering identity. American Society for Engineering Education Annual Conference, New Orleans, LA.

Godwin, A., \& Kirn, A. (2020). Identity-based motivation: connections between first-year students' engineering role identities and future-time perspectives. Journal of Engineering Education.

Godwin, A., \& Lee, W. (2017). A cross-sectional study of engineering identity during undergraduate education. American Society for Engineering Education Annual Conference, Columbus, $\mathrm{OH}$.

Godwin, A., Potvin, G., Hazari, Z., \& Lock, R. (2013). Understanding engineering identity through structural equation modeling. Oklahoma City, OK: Frontiers in Education Conference.

Hatmaker, D. M. (2013). Engineering identity: gender and professional identity negotiation among women engineers. Gender, Work \& Organization, 20(4), 382-396.

Hazari, Z., Sonnert, G., Sadler, P. M., \& Shanahan, M. C. (2010). Connecting high school physics experiences, outcome expectations, physics identity, and physics career choice: a gender study. Journal of Research in Science Teaching, 47(8), 978-1003.

Hill, C., Corbett, C., \& St Rose, A. (2010). Why so few? Women in science, technology, engineering, and mathematics. American Association of University Women.

Huang, C. (2013). Gender differences in academic self-efficacy: a meta-analysis. European journal of psychology of education, 28(1), 1-35.

Jones, B. D., Paretti, M. C., Hein, S. F., \& Knott, T. W. (2010). An analysis of motivation constructs with first-year engineering students: relationships among expectancies, values, achievement, and career plans. Journal of Engineering Education, 99(4), 319-336.

Kyriakidou, O. (2011). Negotiating gendered identities through the process of identity construction: Women managers in engineering. Equality, Diversity and Inclusion: An International Journal, 31(1), 27-42.

Lazarides, R., \& Lauermann, F. (2019). Gendered paths into STEM-related and language-related careers: girls' and boys' motivational beliefs and career plans in math and language arts. Frontiers in Psychology, 10, 1243

Lent, R. W., Brown, S. D., \& Larkin, K. C. (1984). Relation of self-efficacy expectations to academic achievement and persistence. Journal of counseling psychology, 31(3), 356-362

Lent, R. W., Sheu, H.-B., Miller, M. J., Cusick, M. E., Penn, L. T., \& Truong, N. N. (2018). Predictors of science, technology, engineering, and mathematics choice options: A meta-analytic path analysis of the social-cognitive choice model by gender and race/ethnicity. Journal of counseling psychology, 65(1), 17.

Mamaril, N. J., \& Royal, K. D. (2008). Women and minorities in engineering: a review of the literature Midwestern Educational Research Association, Columbus, $\mathrm{OH}$.

Marra, R. M., Rodgers, K. A., Shen, D., \& Bogue, B. (2009). Women engineering students and self-efficacy: A multi-year, multi-institution study of women engineering student self-efficacy. Journal of Engineering Education, 98(1), 2738.

Matusovich, H. M., Streveler, R. A., \& Miller, R. L. (2010). Why do students choose engineering? A qualitative, longitudinal investigation of students' motivational values. Journal of Engineering Education, 99(4), 289-303.

Mcllwee, J. S., \& Robinson, J. G. (1992). Women in engineering: Gender, power, and workplace culture. SUNY Press.
Meyers, K. L., Ohland, M. W., Pawley, A. L., Sillman, S. E., \& Smith, K. A. (2012). Factors relating to engineering identity. Global Journal of Engineering Education, 14(1), 119-131.

Morelock, J. R. (2017). A systematic literature review of engineering identity: definitions, factors, and interventions affecting development, and means of measurement. European Journal of Engineering Education, 42(6), 1240-1262.

National Research Council. (2012). Discipline-based educational research: Understanding and improving learning in undergraduate science and engineering. N. A. Press.

National Science Foundation, \& National Center for Science and Engineering Statistics. (2019). Women, Minorities, and Persons with Disabilities in Science and Engineering: 2019 (Special Report NSF 19-304. , Issue. https://www.nsf. gov/statistics/wmpd.

Patrick, A. D., \& Borrego, M. (2016). A review of the literature relevant to engineering identity American Society for Engineering Education Annual Conference, New Orleans, LA.

Patrick, A. D., Borrego, M., \& Prybutok, A. (2018). Predicting persistence in engineering through an engineering identity scale. International Journal of Engineering Education, 34(2(A)), 351-363.

Patrick, A. D., Choe, N. H., Martins, L. L., Borrego, M., Kendall, M. R., \& Seepersad, C. C. (2017). A Measure of Affect toward Key Elements of Engineering Professional Practice American Society for Engineering Education Annual Conference, New Orleans, LA

Patrick, A. D., Riegle-Crumb, C., \& Borrego, M. (2021). Examining the gender gap in engineering professional identification. Journal of Women and Minorities in Science and Engineering, 27(1).

Patrick, A. D., Seepersad, C. C., \& Borrego, M. (2018). A combined model for predicting engineering identity in undergraduate students American Society for Engineering Education Annual Conference. UT: Salt Lake City.

Powell, A., Bagilhole, B., \& Dainty, A. (2009). How women engineers do and undo gender: consequences for gender equality. Gender, Work \& Organization, 16(4), 411-428. https://doi.org/https://doi.org/10.1111/j.1468-0432.2008.00406.

Prybutok, A., Patrick, A. D., Borrego, M., Seepersad, C. C., \& Kirisits, M. J. (2016). Cross-sectional survey study of undergraduate engineering identity. American Society for Engineering Education Annual Conference, New Orleans, LA.

Riegle-Crumb, C., King, B., Grodsky, E., \& Muller, C. (2012). The More Things Change, the More They Stay the Same? Examining Gender Equality in Prior Achievement and Entry into STEM College Majors over Time. American Educational Research Journal, 49(6), 1048-1073. https://doi.org/https://doi.org/ 10.3102/0002831211435229

Riegle-Crumb, C., Moore, C., \& Ramos-Wada, A. (2011). Who wants to have a career in science or math? Exploring adolescents' future aspirations by gender and race/ethnicity. Science Education, 95(3), 458-476.

Robinson, K. A., Lee, Y.-k., Bovee, E. A., Perez, T., Walton, S. P., Briedis, D., \& Linnenbrink-Garcia, L. (2019). Motivation in transition: development and roles of expectancy, task values, and costs in early college engineering. Journal of Educational Psychology, 111(6), 1081.

Rodriguez, S. L., Lu, C., \& Bartlett, M. (2018). Engineering identity development: a review of the higher education literature. International Journal of Education in Mathematics, Science and Technology, 6(3), 254-265.

Rottinghaus, P. J., Larson, L. M., \& Borgen, F. H. (2003). The relation of selfefficacy and interests: a meta-analysis of 60 samples. Journal of Vocational Behavior, 62(2), 221-236. https://doi.org/https://doi.org/10.1016/ s0001-8791(02)00039-8

Sadler, P. M., Sonnert, G., Hazari, Z., \& Tai, R. (2012). Stability and volatility of STEM career interest in high school: A gender study. Science Education, 96(3), 411427.

Sheppard, S., Antonio, A. L., Brunhaver, S. R., \& Gilmartin, S. (2014). Studying the career pathways of engineers. In A. Johri \& B. M. Olds (Eds.), Cambridge handbook of engineering education research (pp. 283-309). Cambridge University Press.

Stout, J. G., Dasgupta, N., Hunsinger, M., \& McManus, M. A. (2011). STEMing the tide: using ingroup experts to inoculate women's self-concept in science, technology, engineering, and mathematics (STEM). Journal of personality and social psychology, 100(2), 255-270. https://doi.org/https://doi.org/10.1037/ a0021385

Wang, M.-T., \& Degol, J. L. (2013). Motivational pathways to STEM career choices: Using expectancy-value perspective to understand individual and gender differences in STEM fields. Developmental Review, 33(4), 304-340. 
Wang, M.-T., \& Degol, J. L. (2017). Gender gap in science, technology, engineering, and mathematics (STEM): Current knowledge, implications for practice, policy, and future directions. Educational Psychology Review, 29(1), $119-140$.

Wegemer, C. M., \& Eccles, J. S. (2019). Gendered STEM career choices: altruistic values, beliefs, and identity. Journal of Vocational Behavior, 110, 28-42

Welkowitz, J., Cohen, B. H., \& Ewen, R. B. (2006). Introductory statistics for the behavioral sciences (6th ed. ed.). John Wiley \& Sons, Inc.

Wigfield, A., \& Eccles, J. S. (2000). Expectancy-value theory of achievement motivation. Contemporary Educational Psychology, 25(1), 68-81.

Xie, Y., Fang, M., \& Shauman, K. (2015). STEM Education. Annual Review of Sociology, 41(1), 331-357. https://doi.org/https://doi.org/10.1146/annurev-soc$071312-145659$

Yoder, B. L. (2017). Engineering by the numbers: ASEE retention and time-tograduation benchmarks for undergraduate engineering schools, departments and programs.

\section{Publisher's Note}

Springer Nature remains neutral with regard to jurisdictional claims in published maps and institutional affiliations.

\section{Submit your manuscript to a SpringerOpen ${ }^{\circ}$ journal and benefit from:}

- Convenient online submission

- Rigorous peer review

- Open access: articles freely available online

- High visibility within the field

- Retaining the copyright to your article

Submit your next manuscript at $\boldsymbol{\wedge}$ springeropen.com 